\title{
Penguatan Citra Destinasi Melalui Pemasaran Kota, Event Wisata dan Pemasaran Media Sosial
}

\author{
Aisah Asnawi ${ }^{1}$, Fajra Octrina ${ }^{2}$, Jatnika Dwi Asri ${ }^{3}$ \\ ${ }^{1}$ Universitas Pattimura, cheasnawi@yahoo.com \\ ${ }^{2}$ Politeknik LP3I Bandung, fajraoctrina@plb.ac.id \\ ${ }^{3}$ Institut Pemerintahan Dalam Negeri, nickeaja@gmail.com
}

\begin{abstract}
ABSTRAK
Penguatan citra destinasi wisata dapat dilakukan melalui strategi pemasaran kota/kab, event wisata dan pemasaran media sosial yang efektif. Saat ini, kompetisi antar kota/kab terus meningkat terutama di bidang pariwisata melalui kebijakan pemasaran kota yang ramah wisatawan, event wisata yang ikonik serta pemasaran media sosial yang masif. Citra destinasi yang kuat akan berimbas pada peningkatan jumlah kunjungan dan loyalitas wisatawan. Adapun tujuan dari penelitian ini adalah untuk menganalisis pengaruh hubungan pemasaran kota/kabupaten, event wisata dan pemasaran media sosial untuk menguatkan citra destinasi wisata di Maluku. Metodologi dalam penelitian ini didasarkan pada analisis kuantitatif dengan menggunakan Structural Equation Model (SEM) Lisrel 8,2 untuk mengkonfirmasi teori dan melihat hubungan variabel pemasaran kota/kabupaten, event wisata, pemasaran media sosial dan citra destinasi. Hasil dari penelitian ini menunjukkan bahwa pemasaran kota/kabupaten memiliki pengaruh lebih tinggi dalam menguatkan citra destinasi dibandingkan event wisata dan pemasaran media sosial. Hal ini menunjukkan bahwa strategi yang efektif dari pemerintah dalam memajukan pariwisata lebih berimbas langsung dan kuat mempengaruhi citra sebuah destinasi.

Kata Kunci: Pemasaran Kota, Event Wisata, Pemasaran Media Sosial, Citra Destinasi.
\end{abstract}

\begin{abstract}
Strengthening the image of a tourist destination can be done through city/district marketing strategies, tourism events, and effective social media marketing. At present, competition between cities/districts continues to increase, especially in city marketing that tourist-friendly, iconic tourism events and massive social media marketing. The strong of destination image will impact on increasing the number of visits and tourist loyalty. The research objective of this study is to analyze the relationship between city / regency marketing, social media events to strengthen the image of tourist destinations in Maluku. The methodology in this research is based on quantitative analysis using the Lisrel 8.2 Structural Equation Model (SEM) to discuss theory and see the relationship between city/district marketing variables, tourism events, social marketing media, and destination imagery. The results of this study indicate that city/district marketing has a greater increase in strengthening the image of destinations compared to tourism events and social media marketing. This shows an effective strategy from the government in advancing tourism faster and stronger in increasing the image of a destination.
\end{abstract}

Keywords: City Marketing, Tourism Events, Social Media Marketing, Destination Image.

Diterima: 20 Agustus 2019, Direvisi: 16 Oktober 2019, Diterbitkan: 15 Februari 2020 


\section{PENDAHULUAN}

Di Indonesia, pariwisata telah memberikan sumbangan signifikan bagi peningkatan devisa. Pada tahun 2011-2012, pariwisata menjadi penyumbang devisa nomor lima setelah sektor minyak dan gas bumi, batubara, minyak kelapa sawit, dan karet olahan. Pada tahun 2013-2015 sektor pariwisata meningkat ke peringkat empat kontributor devisa nasional dan pada tahun 2016 sektor ini menjadi penyumbang devisa terbesar kedua setelah minyak sawit mentah. (https://finance.detik.com/-akses 22/12/2017). Untuk mengetahui kontribusi sektor pariwisata terhadap devisa dari tahun 2015-2018 dapat dilihat pada tabel 1

Tabel 1.

Penerimaan Devisa Nasional Dari Sektor Pariwisata

\begin{tabular}{ccrr} 
Tahun & $\begin{array}{c}\text { Jumlah } \\
\text { Wisman }\end{array}$ & $\begin{array}{l}\text { Devisa } \\
\text { Wisman } \\
\text { (Juta US\$) }\end{array}$ & Peningkatan \\
\hline 2011 & $7,649,731$ & $8,554.39$ & $12,5 \%$ \\
\hline 2012 & $8,044,462$ & $9,120.89$ & $6,6 \%$ \\
\hline 2013 & $8,802,129$ & $10,054.15$ & $10,2 \%$ \\
\hline 2014 & $9,435,411$ & $11,166.13$ & $11,1 \%$ \\
\hline 2015 & 9.729 .350 & $11,900.00$ & $6,6 \%$ \\
\hline 2016 & 11.519 .275 & $13,230.76$ & $11,2 \%$ \\
\hline 2017 & $14,039,799$ & $16,800.00$ & $26,9 \%$ \\
\hline 2018 & $15,810.305$ & $17,600.00$ & $4,7 \%$
\end{tabular}

Sumber: www.kemenpar.go.id

Untuk meningkatkan pariwisata dan kompetisi antar destinasi, citra merupakan faktor penting dan sangat berpengaruh terhadap kunjungan karena berpengaruh dalam mempertahankan pangsa pasar wisatawan, promosi serta sensivitas harga dan layanan antara repeat dan first time tourist (Alegre \& Juaneda, 2006). Citra destinasi memainkan peranan penting terhadap keputusan kunjungan pertama kali dalam berwisata. (Kaplanidou \& Vogt, 2010) Oleh sebab itu, citra positif selama kunjungan dapat meningkatkan kemungkinan kunjungan ulang. (Pike, 2008) dan (Daleela, Wahid, \& Khasimah, 2016). Banyak penelitian yang membahas tentang pariwisata karena kepariwisataan bersifat multidimensi, multisektor, dan multiskill sehingga dapat memberikan multiefek yang besar dari sisi ekonomi dan sosial. Nilai dasar dari pariwisata adalah "spending" karena memiliki multiply effect terhadap berbagai sektor seperti hotel, transportasi, perdagangan, kerajinan, dan pelayanan jasa lainnya. Selain itu, pariwisata sangat terkait dengan investasi dan struktur ekonomi di bidang lainnya. (Tripkovic Markovic, 2010)

Kota-kota menghabiskan anggaran yang besar dalam kebijakan pemasaran untuk menarik kelompok sasaran baru dan menjaga yang sudah ada, oleh sebab itu diferensiasi menjadi semakin penting terutama untuk kota-kota yang lebih kecil. Diferensiasi ini ditujukan untuk menarik visitor karena alasan seseorang memilih berkunjung di satu tempat dibandingkan dengan tempat lainnya sangat subjektif, bukan saja karena atribut, tetapi bisa juga karena sesuatu yang lebih dominan atau hal lainnya. Penelitian Empiris menunjukkan bahwa kebijakan dan strategi kota setiap tahun semakin kompetitif untuk meningkatkan kota sebagai layak tinggal (liveability), layak dikunjungi (visitability) dan layak untuk berinvestasi (investability). Dalam sektor pariwisata, pemasaran kota/kabupaten ditujukan untuk dapat menguatkan citra destinasi dan menarik sebanyak mungkin pengunjung.

Selain itu, salah satu strategi dalam memasarkan destinasi dapat dilakukan melalui penyelenggaraan event sehingga dapat meningkatkan atau membentuk citra positif dari daerah tersebut. Itulah yang mendasari Kemenpar mengeluarkan Calender Of Event $(\mathrm{CoE})$ yang memuat event skala nasional dari setiap provinsi di Indonesia yang menampilkan budaya dan keunggulan daerah. Banyak penelitian empiris yang menyatakan bahwa event wisata efektif dalam mengajak masyarakat berkunjung dan mengurangi citra negatif bahkan membalikkannya menjadi citra positif (Yuan \& Chong, 2007). Jumlah event yang diselenggarakan oleh Dispar Provinsi Maluku meningkat dari tahun 2015 hingga 2018. Selain itu, penyelenggaraan event tidak hanya terpusat di Kota Ambon namun tersebar di berbagai kabupaten/kota di Maluku. Tabel 1.2 di bawah menunjukkan peningkatan jumlah event yang dilaksanakan oleh Provinsi Maluku setiap tahun sejak 2015-2018.

Tabel 2.

Jumlah Penyelenggaraan Event Wisata Di Maluku

\begin{tabular}{cc}
\hline Tahun & $\begin{array}{c}\text { Jumlah Event } \\
\text { Wisata }\end{array}$ \\
\hline 2015 & 18 \\
\hline 2016 & 12 \\
\hline 2017 & 14 \\
\hline 2018 & 23 \\
\hline
\end{tabular}

Sumber: Dinas Pariwisata Provinsi Maluku 
Studi empiris juga membuktikan bahwa pariwisata dan media sosial tidak dapat dipisahkan saat ini. Perkembangan pemasaran media sosial sangat berdampak pada pariwisata. (Zeng \& Gerritsen, 2014) karena penggunaannya bertujuan untuk mempercepat proses interaksi antara produsen informasi dan penerima (Sicilia, Perez, \& Heffernan, 2008). Perkembangan internet menjadikan fungsi media sosial meningkat dari hanya sekedar jejaring untuk berinteraksi menjadi sarana pemasaran yang efektif. Sebagian besar promosi pariwisata saat ini menggunakan media sosial.

Fenomena menarik saat ini adalah peningkatan jumlah website dan blog yang membahas tentang pariwisata, komunitas wisata, review personal tentang wisata dan profesi sebagai traveler dan blogger. Untuk mempromosikan pariwisata dengan biaya murah, Kemenpar mengundang influencer dan blogger media sosial dari berbagai negara untuk mereview destinasi di Indonesia karena kemampuan mereka dalam mempengaruhi para followernya. Selain platform media sosial seperti facebook dan instagram yang sering digunakan, website juga memegang peranan penting dalam memberikan informasi wisata. Secara resmi, masing-masing provinsi memiliki website yang dikelola oleh dinas pariwisata untuk mempromosikan destinasi yang ada di daerahnya. Untuk mensupport pemasaran pariwisata melalui media digital, Kemenpar membuat kategori Promosi Pariwisata Digital Terpopuler (Most Popular Digital Tourism Promotion) dalam ajang Anugerah Pesona Indonesia (API) untuk menilai keseriusan daerah dan komunitas menggunakan media sosial dalam promosi destinasi.

Citra destinasi telah menjadi dominasi wilayah penelitian pemasaran dibidang pariwisata. Bagaimana menarik wisatawan untuk berkunjung kembali dan/atau merekomendasikan tujuan kepada orang lain sangat penting bagi pengembangan destinasi (C. Chen \& Tsai, 2007). Salah satu upaya untuk meningkatkan citra berbagai destinasi di Indonesia yaitu melalui penyelenggaraan kegiatan Anugerah Pesona Indonesia (API) dengan tujuan membangkitkan apresiasi masyarakat serta mendorong daerah lebih berperan dalam mempromosikan pariwisata dan kompetisi antar daerah. Kategori yang dilombakan meningkat setiap tahun. Tahun 2016 terdapat sepuluh kategori yang dilombakan sedangkan tahun 2017 meningkat menjadi lima belas kategori. Pemilihan pemenang berdasarkan voting secara online untuk umum selama periode tertentu. Dalam ajang API di tahun 2016, Maluku sebagai nominator pada tiga kategori yaitu; (1) surga tersembunyi; (2) tujuan wisata terpopuler kebersihannya; dan (3) atraksi budaya terpopuler. Sedangkan tahun 2017, meningkat menjadi enam kategori, yaitu (1) objek wisata bersih terpopuler; (2) tempat menyelam terpopuler; (3) tujuan wisata baru terpopuler; (4) kampung adat terpopuler; (5) objek wisata belanja terpopuler dan (6) objek wisata unik terpopuler.

Berdasarkan pemaparan di atas, maka penelitian ini bertujuan untuk:

1. Memperoleh hasil analisis pengaruh pemasaran kota/kabupaten terhadap citra destinasi wisata.

2. Memperoleh hasil analisis pengaruh event wisata terhadap citra destinasi wisata.

3. Memperoleh hasil analisis pengaruh pemasaran media sosial terhadap citra destinasi wisata.

\section{KAJIAN LITERATUR \\ Pemasaran Kota/Kabupaten}

Studi pemasaran terhadap suatu tempat didasarkan pada dua pendekatan teori yaitu; (1) pemasaran tempat dan ekonomi politik yang lebih menekankan transformasi pemerintah dan keterlibatan komunitas bisnis dalam pengembangan ekonomi; (2) konsentrasi berbagai strategi pemasaran. (Avraham \& Ketter, 2008).

Pada saat ini, variabel pemasaran kota turut sangat penting bagi keputusan seseorang untuk berkunjung ke sebuah tempat/destinasi karena persepsi seseorang terhadap sebuah kota dapat dibentuk. Pemasaran kota saat ini lebih diposisikan sebagai strategi yang digunakan untuk menarik pengunjung/wisatawan serta investor potensial. Sejak pariwisata menjadi sektor penopang guna meningkatkan pendapatan daerah dan didukung oleh UU No.32 tahun 2004 tentang otonomi daerah. Setiap kota atau daerah berusaha menerapkan strategi pemasaran untuk mempromosikan kota/daerahnya

Perbedaan pemasaran destinasi dengan pemasaran tradisional adalah, (1) destinasi lebih menantang untuk di kelola karena kompleksitas hubungan diantara berbagai pihak yang berkepentingan; (2) banyak pihak yang berkepentingan dalam membangun, memproduksi, menghantarkan serta menawarkan pariwisata sehingga tidak ada pemilik keseluruhan proses; (3) stakeholder terkait dalam mempresentasikan destinasi mungkin memiliki konflik kepentingan dan agenda politik sehingga sulit untuk bersinergi. (Line \& Wang, 2016). 
Seiring berlalunya waktu, ide bahwa pemasaran tempat identik dengan pemasaran pada umumnya mulai terkikis. Akibatnya, komunitas, kota, negara, bangsa dan daerah menjadi lebih giat untuk mengadopsi bisnis strategis, manajemen dan konsep-konsep serta alat-alat pemasaran. (Gertner, 2011).

\section{Event Wisata}

Event merupakan motivasi penting dari pariwisata dan berperan dalam pengembangan serta pemasaran sebagian besar destinasi yang akhirnya menjadi karakteristik lokal, khas, unik dan ikon daerah. (Middleton \& Clark, 2001). Event yang direncanakan dan didokumentasikan dengan baik akan berperan dan berdampak positif pada daya saing destinasi (Getz, 2008); (Golob \& Jakulin, 2014). Dalam beberapa tahun terakhir, festival dan event khusus menjadi salah satu jenis yang paling cepat berkembang dalam atraksi wisata (Thrane, 2002) ; (Gursoy, Kim, \& Uysal, 2004). Ada beberapa alasan potensial atas fenomena tersebut, (1) Festival dan event wisata berpengaruh signifikan terhadap ekonomi; (2) sponsor memiliki keyakinan untuk mendapatkan manfaat intangible social lewat keikutsertaan dalam event; (3) mengembangkan festival baru merupakan strategi untuk memperpanjang life cycle sebuah destinasi (Boo \& Busser, 2006). Selain citra positif, events atau festival juga dapat menghapus efek negatif. Sebuah kota yang memiliki citra unik dapat diidentifikasi melalui city mind identity, city visual identity, dan city behavior identity yang berkaitan dengan event dan festival (Yuan Liu \& Chen, 2007).

Pengaruh event dalam aspek sosial, lingkungan dan ekonomi juga dikemukakan oleh Raj \& Musgrave, (2009) dalam gambar 2.2. Dengan demikian dapat disimpulkan bahwa event tidak hanya memiliki efek positif tetapi juga efek negatif yang harus diantisipasi oleh penyelenggara event dan stake holder.

Sedangkan tujuan inti event wisata dapat dijabarkan sebagai berikut (Getz \& Page, 2016):

a) Menarik wisatawan (termasuk sponsor dan media), manfaat ekonomi; mengatasi weak season, menyebarkan geografi pariwisata, dan meningkatkan pembangunan perkotaan dan ekonomi;

b) Menyebarkan citra positif terhadap destinasi dan membangun merek kota serta mereposisi citra kota.

c) Berkontribusi memasarkan destinasi sebagai tempat yang layak tinggal dan atraktif. d) Menggambarkan sebuah kota, resort, taman, ruang-ruang perkotaan dan segala jenis tempat, sehingga mendapatkan kunjungan berulang.

e) Katalis pembangunan, termasuk pembaharuan perkotaan, peningkatan kapasitas masyarakat, kerelawanan dan memperbaiki pemasaran sehingga menghasilkan warisan jangka panjang.

Berdasarkan tipologi event, dapat disimpulkan bahwa hampir semua tipologi memiliki kesamaan. Delapan tipologi event dari Getz (2008); dan Golob\&Jaculin (2014) memiliki kesamaan dalam keseluruhan tipologi. Middleton\&Clark (2001) bahkan memiliki sepuluh tipologi namun berbeda dengan peneliti lain karena lebih ditekankan pada objek event. Dengan demikian dapat disimpulkan bahwa event bukan saja tentang perayaan budaya namun juga perayaan politik, seni, pendidikan, olahraga dan hiburan lainnya. Event yang dapat dikategorikan sebagai event wisata, memiliki ciri-ciri sebagai berikut yaitu: (1) Berbeda dengan atraksi dalam bentuk permanen (patung, pura, gedung), event adalah atraksi atau kegiatan yang hidup; (2) Mempunyai kepastian atau ketentuan kegiatan (fixed time) atau waktu penyelenggaraan; (3) Waktu penyelenggaraan yang pendek dan tidak lama atau seterusnya; (4) Melibatkan masyarakat atau kelompok tertentu sebagai peserta, pengunjung atau penyelenggara; (5) Dapat berdiri sendiri, tanpa harus terikat dengan atraksi permanen. Sedangkan untuk dapat menyelenggarakan sebuah event, maka terdapat tujuh elemen yang yang harus dipenuhi oleh sebuah detinasi, yaitu; (1) infrastruktur; (2) akomodasi; (3) transportasi; (4) atraksi; (5) katering; (6) pedagang pengecer; (7) sarana rekreasi atau hiburan. (Getz, 1991).

\section{Pemasaran Media Sosial}

Internet telah merevolusi bisnis termasuk sektor pariwisata. Review yang dihasilkan dari pengunjung, foto-foto, video, cerita dan rekomendasi, serta pemasaran destinasi secara online memudahkan menjangkau pengunjung potensial. (Kiralova \& Pavlí, 2015). Pemasaran media sosial merevolusi konsep komunikasi destinasi wisata dan berperan penting sebagai sumber informasi wisata (Xiang \& Gretzel, 2010), berperan signifikan pada sisi permintaanpenawaran, memungkinkan destinasi wisata berinteraksi langsung dengan pengunjung, melakukan penawaran, mendapatkan masukan 
dan lebih efisien dalam melakukan evaluasi pelayanan dibandingkan komunikasi tradisional. (Kaplan \& Haenlein, 2010); (Pavlí, 2015).

Kebanyakan penelitian pemasaran media sosial dibidang pariwisata terkait fenomena dari perspektif wisatawan (Ayeh, Leung, Au, Law 2012) serta relevansinya terhadap perilaku dan pencarian informasi perjalanan. Penelitian tentang topik ini menunjukkan bahwa calon wisatawan lebih percaya pada kredibilitas blog dibandingkan dengan world of mouth secara tradisional (Litvin, Goldsmith, \& Pan, 2008), hubungan antara blogging dan sentimen positif terhadap iklan website, dampak dari situs media sosial pada pencarian informasi wisata (Huang, Chou, \& Lin, 2010), dan meningkatnya peran word of mouth secara elektronik (Xiang \& Gretzel, 2010).

Konsumen menggunakan media sosial untuk memposting cerita, komentar dan evaluasi, gambar dan klip video. Wisatawan membagikan evaluasi dan persepsi mereka tentang sebuah destinasi dengan kecenderungan mempengaruhi pilihan destinasi bagi orang lain yang menjadi wisatawan potensial di seluruh dunia. Media sosial digunakan sebelum, selama dan setelah liburan untuk berbagi pengalaman dan merupakan sumber informasi yang signifikan.(Kladou \& Mavragani, 2015)). Fenomena yang terjadi saat ini, WoM secara elektronik sangat ditekankan, karena konten media sosial dianggap lebih dapat dipercaya daripada situs web pariwisata resmi atau iklan di media konvensional (Fotis et al., 2012).

\section{Citra Destinasi}

Kekuatan merek adalah aset dalam strategi pasar global. Banyak peneliti memberikan kontribusi berbeda terhadap pemahaman citra destinasi selama 30 tahun terakhir. Citra destinasi telah menjadi dominasi wilayah penelitian pemasaran dibidang pariwisata. Bagaimana menarik wisatawan untuk berkunjung kembali dan/atau merekomendasikan tujuan kepada orang lain sangat penting bagi pengembangan destinasi (C. Chen \& Tsai, 2007).

Sebagai konsekuensi dari meningkatnya persaingan dibidang pariwisata, citra destinasi menjadi elemen kunci dalam upaya diferensiasi antar destinasi (Hosany, Ekinci, \& Uysal, 2006). Citra destinasi menjadi isu penting dalam penelitian di industri wisata. Hal ini dimulai ketika banyak negara menggunakan konsep pemasaran global untuk mempromosikan dan mensupport citra destinasi agar dapat berkompetisi dengan destinasi lainnya. (Huang \& Lin, 2009). Pentingnya citra destinasi diakui mampu mempengaruhi persepsi subjektif individu dan perilaku konsumen terhadap suatu destinasi. (Kaur \& Chauhan, 2016).

Sebagian besar peneliti memahami konsep citra destinasi sebagai perilaku yang dibentuk oleh elemen kognitif, afektif dan konatif dimana masing-masing elemen merupakan bagian dari konstrak perilaku dan terbukti berpengaruh pada perilaku konsumen.

Berdasarkan kajian literatur di atas, maka dibangun model hipotesis sebagai berikut:

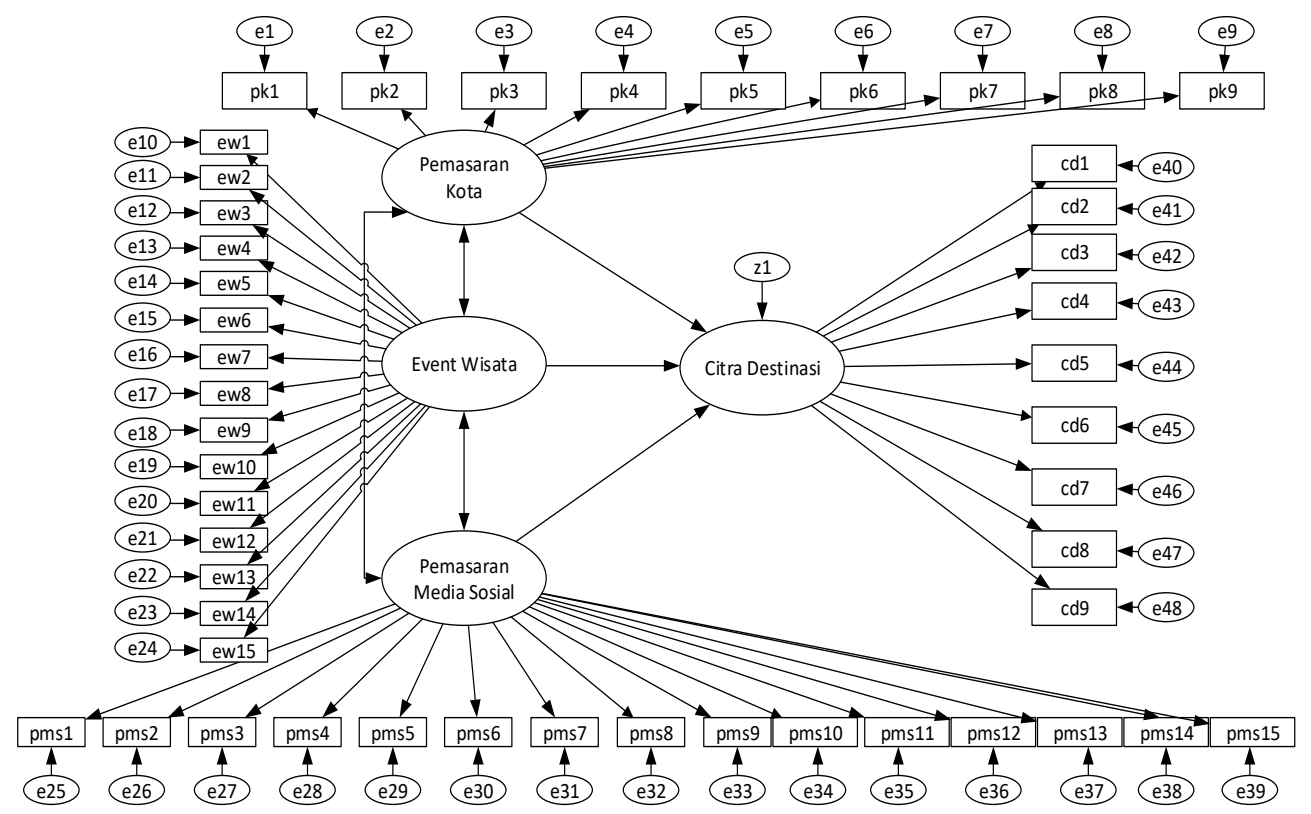

Gambar 1. Model Hipotesis 


\section{METODOLOGI PENELITIAN}

Penelitian ini menggunakan metode verifikatif dengan alat analisis Structural Equation Modeling (SEM) Lisrel 8.2. Rentang waktu penelitian adalah cross sectional one shot yang berarti informasi atau data penelitian ini didapatkan pada rentang waktu tertentu. Unit observasi dari penelitian adalah wisatawan nusantara dan wisatawan mancanegara dengan tujuan wisata, event wisata maupun MICE (meeting, incentive, convention dan exhibition). Jumlah wisatawan yang menjadi responden adalah 595 orang wisatawan nusantara yang berkunjung ke Maluku.

\section{HASIL DAN PEMBAHASAN}

Pengaruh Pemasaran Kota, Event Wisata dan Pemasaran Media Sosial Terhadap Citra Destinasi

Dari hasil perhitungan untuk hipotesis pengaruh pemasaran kota/kab, event wisata dan pemasaran media sosial terhadap citra destinasi diperoleh persamaan struktural yang dihipotesiskan sebagai berikut:

$$
\begin{aligned}
& \eta 1=\gamma 11 \xi 1+\gamma 12 \xi 2+\gamma 13 \xi 3+\zeta 1 \\
& \eta 1=0,53 \xi_{1}+0,36 \xi_{2}+0,24 \xi_{3}+\zeta_{1}
\end{aligned}
$$

Tabel berikut menunjukkan hasil pengujian secara simultan dari pemasaran kota/kab, Event Wisata dan Pemasaran Media Sosial terhadap Citra Destinasi.

Tabel 3.

Pengujian Hipotesis Pengaruh Simultan

Pemasaran Kota/Kab, Event Wisata dan

Pemasaran Media Sosial Terhadap Citra Destinasi

\begin{tabular}{lcc}
\hline Model Struktural & $\begin{array}{c}\text { Koefisien } \\
\text { Determinasi } \\
/ \mathbf{R}^{2}\end{array}$ & F hitung \\
\hline Pemasaran kota/kab, & 0.77 & $664.61^{*}$ \\
Event Wisata dan & & \\
Pemasaran Media & & \\
Sosial-> Citra \\
Destinasi \\
* signifikan pada $\alpha=0,05(\mathrm{~F}$ tabel $=2.62)$
\end{tabular}

Hasil pengujian hipotesis secara simultan menunjukkan secara keseluruhan, variabel pemasaran kota/kab $(\xi 1)$, event wisata ( $\xi 2)$, dan pemasaran media sosial $(\xi 3)$ berpengaruh secara simultan terhadap variabel citra destinasi $(\eta 1)$ sebesar 77\% dengan kriteria sangat kuat (Chin, 1988). Oleh sebab itu, disimpulkan bahwa hasil pengujian menggambarkan perubahan pada pemasaran kota/kab, event wisata dan pemasaran media sosial secara bersama-sama mampu meningkatkan citra destinasi.

\section{Pengaruh Pemasaran Kota Terhadap Citra Destinasi}

Berdasarkan hasil uji secara parsial maka hipotesis variabel pemasaran kota/kab $(\xi 1)$ memiliki berpengaruh signifikan terhadap Citra Destinasi ( $\eta 1$ ) dengan total pengaruh sebesar 39.9\% dengan krietria kuat (Chin, 1988). Hasil pengujian ini menggambarkan pemasaran kota/kab memiliki pengaruh yang signifikan terhadap citra destinasi dengan t hitung (4.42) lebih besar dari $t$ tabel (1.96). Hal ini menunjukkan hipotesis diterima. Untuk lebih jelasnya dapat digambarkan sebagai berikut:

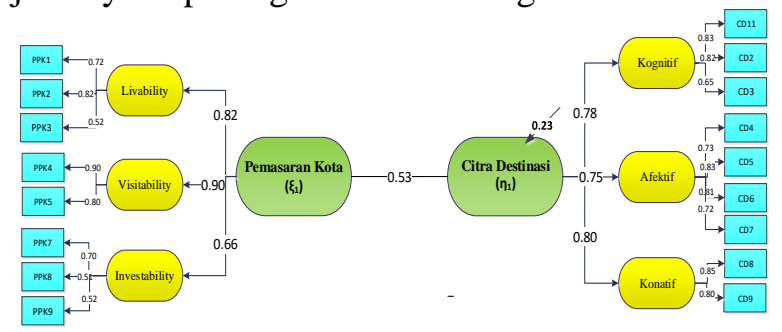

Gambar 2.

Hasil Pengujian Pengaruh Pemasaran Kota/Kab Terhadap Citra Destinasi Wisata

Pada Gambar 2 didapat hasil penelitian yang menunjukkan bahwa pemasaran kota/kab yang terdiri dari livability, visitability dan investability berpengaruh terhadap citra destinasi. Hal ini disebabkan oleh kebijakan pemerintah daerah dalam pengembangan provinsi agar sejajar dengan provinsi lainnya. Dimensi yang tertinggi membentuk citra destinasi adalah visitability dengan nilai 0,90 . Sedangkan dimensi livability berperan dalam meningkatkan citra destinasi sebesar 0,82. Hal ini disebabkan oleh pengembangan infrastruktur berupa perbaikan sarana, prasarana dan akses ke beberapa destinasi berimbas pada sektor pariwisata. Untuk dimensi investability dengan nilai 0,66 menunjukkan bahwa perkembangan ekonomi dan investasi juga berkembang sehingga kota Ambon tidak tertinggal dengan kota-kota lainnya. Investability dalam pemasaran kota/kab berperan dalam meningkatkan kepercayaan investor dan peluang usaha agar terjadi peningkatan ekonomi di daerah destinasi. Hal ini sejalan dengan Balencourt \& Zafra, (2012) yang menyimpulkan bahwa strategi pemasaran kota/kab dalam hal perbaikan ekonomi daerah dan sektor pariwisata secara signifikan meningkatkan citra sebuah destinasi.Sebagai 


\section{Pengaruh Event Wisata Terhadap Citra Destinasi}

Berdasarkan hasil uji secara parsial maka hipotesis Event Wisata ( $(2)$ berpengaruh signifikan terhadap citra destinasi $(\eta 1)$ dengan total pengaruh sebesar $23.8 \%$ dengan kriteria moderate. Hasil pengujian ini menggambarkan event wisata memiliki pengaruh yang signifikan terhadap citra destinasi dengan $\mathrm{t}$ hitung (3.90) lebih besar dari $\mathrm{t}$ tabel (1.96). Hal ini menunjukkan hipotesis diterima. Untuk lebih jelasnya dapat digambarkan sebagai berikut:

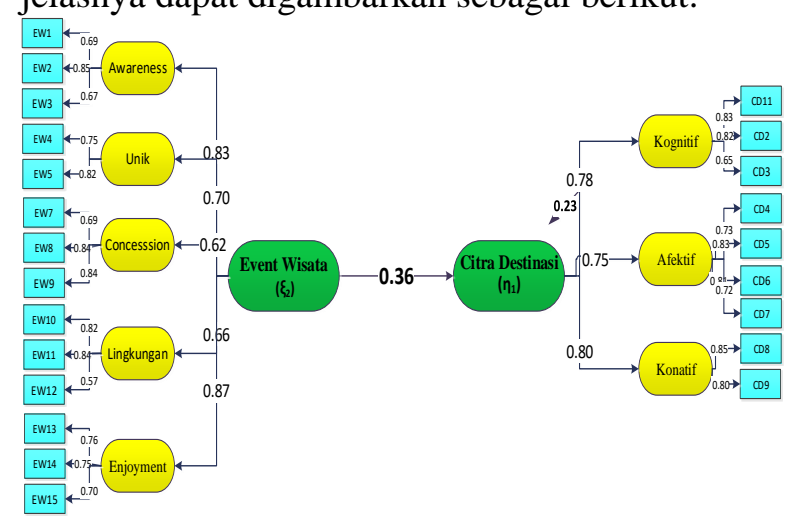

Gambar 3.

Hasil Pengujian Pengaruh Event Wisata Terhadap Citra Destinasi Wisata

Pada Gambar 3 diperoleh hasil penelitian yang menunjukkan bahwa event wisata yang diukur melalui awareness, unik, konsesi/manfaat, kesiapan lingkungan dan enjoyment/escape berpengaruh terhadap citra destinasi.

Nilai tertinggi dalam variabel event wisata dalam membentuk citra destinasi adalah enjoyment dengan nilai 0,87 . Hal ini disebabkan karena wisatawan dan pengunjung merasakan kesenangan dan menikmati event yang dilaksanakan. Sebuah event adalah perayaan yang mampu menghibur dan memberi pengalaman oleh sebab itu, aspek ini sangat penting bagi peserta atau wisatawan. Hal ini sejalan dengan penyataan dari Getz \& Page (2016) bahwa salah satu tujuan mengikuti event adalah peserta berusaha menemukan penghargaan pribadi dan antar pribadi dan berharap untuk melarikan diri dari aspek lingkungan, pribadi dan antarpribadi yang mengganggu atau membuat mereka bosan.

Dengan demikian, event merupakan motivasi penting dari pariwisata dan berperan dalam pengembangan serta pemasaran sebagian besar destinasi (Middleton \& Clark, 2001). Event juga bertujuan untuk menarik wisatawan dan menyebarkan citra positif (Getz \& Page, 2016) dan berkontribusi pada pemasaran destinasi karena membantu menciptakan atau memelihara citra suatu destinasi. Lebih khusus lagi, event dapat digunakan untuk membantu mempromosikan, memposisikan, dan membangun merek destinasi. (Dimanche, 2002). Namun hasil penelitian dari Boo \& Busser, (2006) tentang kontribusi event terhadap citra destinasi menunjukkan bahwa event yang diselenggarakan di Macau tidak berpengaruh positif terhadap citra destinasi pada para peserta.

\section{Pengaruh Pemasaran Media Sosial terhadap Citra Destinasi}

Berdasarkan hasil uji secara parsial maka hipotesis pemasaran media sosial ( $\xi 3$ ) berpengaruh signifikan terhadap citra destinasi ( $\eta 1)$ dengan total pengaruh sebesar $13.4 \%$ dengan kriteria sangat lemah. Hasil pengujian ini menggambarkan pemasaran media sosial memiliki pengaruh yang signifikan terhadap citra destinasi dengan $t$ hitung (3.13) lebih besar dari t tabel (1.96). Walaupun lemah, namun hipotesis diterima karena memiliki pengaruh yang signifikan. Untuk lebih jelasnya dapat digambarkan sebagai berikut:

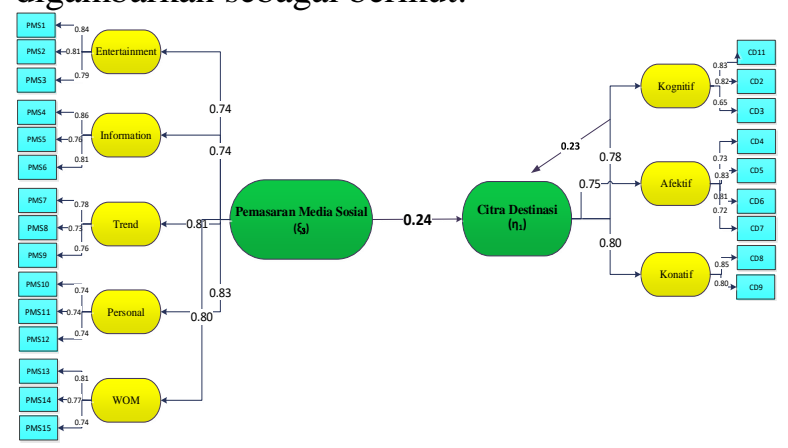

Gambar 4.

Hasil Pengujian Pengaruh Pemasaran Media Sosial Terhadap

Citra Destinasi Wisata

Pada gambar 4 diperoleh hasil penelitian yang menunjukkan bahwa pemasaran media sosial yang diukur melalui hiburan, informasi, trendi, personalisasi dan word of mouth terbukti berpengaruh terhadap citra destinasi wisata. Pemasaran media sosial berpengaruh terhadap citra destinasi wisata di Maluku karena beberapa hal, diantaranya penggunaan media sosial yang masif dalam berinteraksi, kehidupan sosial, bisnis dan pekerjaan. Selain itu, bertambahnya komunitas dan pelaku usaha pariwisata dalam membuat review, foto, video dan cerita tentang destinasi Maluku ternyata berdampak pada citra Maluku. 
Dalam perhitungan ini, pengaruh media sosial terhadap citra destinasi sebesar $13,5 \%$ dan merupakan variabel yang paling rendah pengaruhnya dibandingkan event wisata sebesar $28,3 \%$. Belum maksimalnya penggunaan media sosial dalam mempromosikan destinasi oleh dinas pariwisata Maluku saat ini juga disinyalir sebagai rendahnya pengaruh terhadap citra destinasi. Saat ini promosi wisata Maluku lebih cenderung dilakukan oleh komunitas tour quide, pemilik resort dan komunitas pariwisata lainnya. Mereka juga mengandalkan pertemanan dan networking dengan pihak lain tanpa difasilitasi oleh dinas pariwisata provinsi. Walaupun jumlah penggunaan media sosial cukup meningkat namun hal ini belum sejalan dengan keinginan pemerintah Provinsi untuk lebih serius menggunakan media sosial dalam meningkatkan citra pariwisata Maluku. Hal ini dibuktikan dengan alamat situs resmi parwisata Maluku yang berubah-ubah dan konten informasi yang belum komprehensif.

Media sosial mempermudah promosi wisata karena pemasaran media sosial ikut merevolusi konsep komunikasi destinasi wisata dan berperan penting sebagai sumber informasi wisata (Xiang \& Gretzel, 2010). Review yang dihasilkan dari pengunjung, foto-foto, video, cerita dan rekomendasi, serta pemasaran destinasi secara online memudahkan menjangkau pengunjung potensial. (Kiralova dan Pavli, 2015). Penelitian yang dilakukan oleh Mariani dan Mura (2016) bahkan mempertegas hubungan variabel pemasaran media sosial dan citra destinasi. Penelitian menggunakan mix methode menghasilkan kesimpulan bahwa pemasaran media sosial berkontribusi membangun citra destinasi yang positif. Demikian juga penelitian yang dilakukan oleh Kim, Lee, Shin, \& Yang, (2017) yang mempertegas pengaruh kualitas informasi di media sosial dan website milik pemerintah dalam meningkatkan citra dan mempengaruhi seseorang untuk berkunjung atau tidak ke sebuah destinasi.

Penelitian ini sejalan dengan penelitian dari Werner (2016), (Liu, 2015) dan Dimanche (2016) yang menyatakan bahwa event wisata berpengaruh terhadap citra destinasi. Selain itu, penelitian ini juga sejalan dengan Tham (2013), Mariani (2015) dan Jabreel (2016). Yang menyatakan bahwa pemasaran media sosial berpengaruh terhadap citra destinasi. Jika dilihat dari fenomena yang terjadi saat ini, pemasaran media sosial dapat menjadi sarana promosi berbudget rendah yang dapat menjadi alternatif dalam meningkatkan citra destinasi wisata. Namun ternyata efektifitas event wisata yang memakan biaya masih dinilai tinggi dalam persepsi wisatawan.

\section{KESIMPULAN DAN REKOMENDASI}

Pemasaran kota/kab berpengaruh signifikan terhadap citra destinasi melalui livability (layak tinggal), visitability (layak dikunjungi) dan investability (layak investasi). Hal ini sejalan dengan komitmen pemerintah daerah untuk meningkatkan sektor pariwisata sebagai sektor unggulan. Event wisata berpengaruh signifikan terhadap citra destinasi melalui kesadaran masyarakat terhadap penyelenggaraan event, keunikan event, manfaat, dan kesiapan penyelenggaraan event. Penyelenggaraan event di Maluku meningkat secara kuantitas dan kualitas. Tahun 2018 terdapat empat event dengan skala internasional dan tiga event yang masuk dalam calender of event nasional. Manfaat yang didapat lewat pelaksanaan calender of event oleh Kemenpar adalah promosi yang luas terhadap event yang dilaksanakan di Maluku dan makin dikenalnya Maluku sebagai destinasi wisata. Selain itu meningkatnya citra Maluku juga disebabkan karena rangkaian event internasional yang dilaksanakan oleh kementrian selama dua tahun dari tahun 2017-2018 melalui Wonderful Sail Indonesia. Pada event ini, 120 yacht dari lima belas negara menyinggahi tiga kabupaten di Maluku dan daerah-daerah lain di Indonesia. Ini merupakan event skala dunia yang cukup mengangkat citra Maluku sebagai destinasi bahari karena selama tiga hari peserta diajak untuk menikmati destinasi wisata, seni dan budaya Maluku. Berdasarkan pengamatan di lokasi kegiatan dan wawancara, peserta sangat senang ikut dalam kegiatan tersebut karena mendapat kesempatan untuk melihat secara langsung keindahan Maluku dan persepsi mereka sangat positif terhadap Maluku sebagai daerah destinasi wisata yang menarik.

Dimensi personalisasi dalam pemasaran media sosial memiliki nilai tertinggi dalam membentuk citra destinasi. Hal ini disebabkan karena media sosial sangat berperan dalam memberikan informasi yang bersifat personal kepada wisatawan berdasarkan preferensi berwisata masing-masing wisatawan. Promosi destinasi menjadi lebih efektif jika dilakukan melalui platform media sosial yang langsung diarahkan kepada wisatawan sesuai target market. Wisatawan juga cenderung mencari informasi spesifik tentang destinasi yang menjadi tujuan 
dan membandingkannya dengan destinasi lain yang sejenis. Bahkan beberapa kunjungan ke destinasi cenderung diakibatkan karena pengaruh media sosial. Oleh sebab itu, personalisasi dapat membantu menguatkan citra destinasi agar lebih menarik bagi wisatawan.

Studi kualitatif dan kuantitatif tentang pemasaran kota/kab, event wisata dan pemasaran media sosial dalam pariwisata masih diperlukan untuk menunjukkan kontribusi terhadap aspek ekonomi berupa peningkatan Pendapatan Asli Daerah (PAD) ataupun devisa negara. Penelitian selanjutnya yang dapat dikembangkan dalam ranah pariwisata seperti jumlah wisatawan, pola perjalanan, perilaku belanja, perspektif pemangku kepentingan, citra destinasi dan pengembalian ekonomi dari investasi.

\section{DAFTAR PUSTAKA}

Alegre, J., \& Juaneda, C. (2006). DESTINATION LOYALTY Consumers' Economic Behavior. Annals of Tourism Research, 33(3), 684-706. https://doi.org/10.1016/j.annals.2006.03.014

Avraham, E., \& Ketter, E. (2008). Media Strategies For Marketing Places In Crisis.

Boo, S., \& Busser, J. A. (2006). IMPACT ANALYSIS OF A TOURISM FESTIVAL ON TOURISTS DESTINATION IMAGES, 9, 223-237.

Daleela, S., Wahid, M., \& Khasimah, N. (2016). First-time and Repeat Visitors to Langkawi Island, Malaysia. Procedia Economics and Finance, 35(October 2015), 622-631. https://doi.org/10.1016/S22125671(16)00076-9

Dimanche, F. (2016). From attractions to experiential marketing - The contributions of events to New Tourism From attractions to experiential marketing: The contributions of events to "New" Tourism, (March).

Gertner, D. (2011). A ( tentative ) meta-analysis of the 'place marketing' and 'place branding ' literature. Journal of Brand Management, 19(January), 112-131. https://doi.org/10.1057/bm.2011.13

Getz, D. (2008). Event tourism : Definition , evolution , and research, 29, 403-428. https://doi.org/10.1016/j.tourman.2007.07.0 17

Getz, D., \& Page, S. J. (2016). Progress and prospects for event tourism research. Tourism Management, 52, 593-631. https://doi.org/10.1016/j.tourman.2015.03.0
07

Golob, A., \& Jakulin, T. J. (2014). STANDARDIZATION AND CLASSIFICATION OF EVENTS, 11(1), 67-73.

Gursoy, D., Kim, K., \& Uysal, M. (2004). Perceived impacts of festivals and special events by organizers: an extension and validation, $25, \quad 171-181$. https://doi.org/10.1016/S02615177(03)00092-X

Jabreel, M., Moreno, A., \& Huertas, A. (2016). Journal of Destination Marketing \& Management Semantic comparison of the emotional values communicated by destinations and tourists on social media. Journal of Destination Marketing \& Management, 1-14.

https://doi.org/10.1016/j.jdmm.2016.03.004

Kaplan, A. M., \& Haenlein, M. (2010). Users of the world, unite! The challenges and opportunities of Social Media. https://doi.org/10.1016/j.bushor.2009.09.00 3

Kaplanidou, K., \& Vogt, C. (2010). The Meaning and Measurement of a Sport Event Experience Among Active Sport Tourists. Journal of Sport Management, 544-566.

Kim, S.-E., Lee, K. Y., Shin, S. Il, \& Yang, S.-B. (2017). Effects of tourism information quality in social media on destination image formation: The case of Sina Weibo. Information \& Management, 54(6), 687702.

https://doi.org/10.1016/j.im.2017.02.009

Kiralova, A., \& Pavlí, A. (2015). Development of Social Media Strategies in Tourism Destination. Procedia - Social and Behavioral Sciences 175 ( 2015 ) $358-366$ International, $\quad 175, \quad 358-366$. https://doi.org/10.1016/j.sbspro.2015.01.12 11

Kladou, S., \& Mavragani, E. (2015). Journal of Destination Marketing \& Management Assessing destination image: An online marketing approach and the case of TripAdvisor. Journal of Destination Marketing \& Management, (2008), 1-7. https://doi.org/10.1016/j.jdmm.2015.04.003

Line, N. D., \& Wang, Y. (2016). Journal of Destination Marketing \& Management A multi-stakeholder market oriented approach to destination marketing. Journal of 
Destination Marketing \& Management, (1), $1-10$. https://doi.org/10.1016/j.jdmm.2016.03.003 Litvin, S. W., Goldsmith, R. E., \& Pan, B. (2008). Electronic word-of-mouth in hospitality and tourism management, $29,458-468$.

https://doi.org/10.1016/j.tourman.2007.05.0 11

Liu, Y. (2015). Major event and city branding An evaluation of Liverpool as the 2008 European Capital of Culture, 8(2), 147-162. https://doi.org/10.1108/JPMD-02-20150007

Mariani, M. M., Buhalis, D., Longhi, C., \& Vitouladiti, O. (2015). Managing change in tourism destinations: Key issues and current trends. Journal of Destination Marketing \& Management, 2(4), 269-272.

Mariani, M. M., Di, M., \& Mura, M. (2016). Facebook as a destination marketing tool: Evidence from Italian regional Destination Management Organizations. Tourism Management, 54, 321-343.

https://doi.org/10.1016/j.tourman.2015.12.0 08

Middleton, Vi., \& Clark, J. R. (2001). Marketing in Travel and Tourism (Third Edit). Butterworth Heinemann.

Pavlí, A. (2015). Development of Social Media Strategies in Tourism Destination. Procedia - Social and Behavioral Sciences 175 ( 2015 ) 358 - 366 International, 175, 358-366. https://doi.org/10.1016/j.sbspro.2015.01.12 11

Pike, S. (2008). Destination Marketing. An Integrated marketing Communication Approach.

Tham, A., Croy, G., Mair, J., \& Croy, G. (2013). Social Media in Destination Choice: Distinctive Electronic Word-of-Mouth Dimensions Social Media In Destination Choice: Distinctive Electronic Word-OfMouth, (October), 37-41. https://doi.org/10.1080/10548408.2013.751 272

Tripkovic Markovic, A. (2010). Tourism Planning: Contribution of Tourism To Socio-Economic Development of Montenegro. Tourism and Hospitality Management, 1289-1304.

Xiang, Z., \& Gretzel, U. (2010). Role of social media in online travel information search. Tourism Management, 31(2), 179-188. https://doi.org/10.1016/j.tourman.2009.02.0
16

Yuan, L. I. U., \& Chong, C. (2007). The effects of festivals and special events on city image design, $1(2)$, 255-259. https://doi.org/10.1007/s11709-007-0032-0

Zeng, B., \& Gerritsen, R. (2014). What do we know about social media in tourism? A review. TMP, 10, 27-36. https://doi.org/10.1016/j.tmp.2014.01.001

\section{BIODATA PENULIS}

Aisah Asnawi. Dosen pada Fakultas Ekonomi dan Bisnis Universitas Pattimura. Bidang riset saat ini adalah pemasaran, pariwisata, dan industri kreatif.

Fajra Octrina. Dosen tetap pada Program Studi Administrasi Bisnis, Politeknik LP3I Bandung dengan bidang riset tentang efisiensi perbankan dan keuangan.

Jatnika Dwi Asri. Dosen tetap pada Institut Pemerintahan Dalam Negeri Bandung dengan bidang riset tentang strategi dan keuangan daerah. 